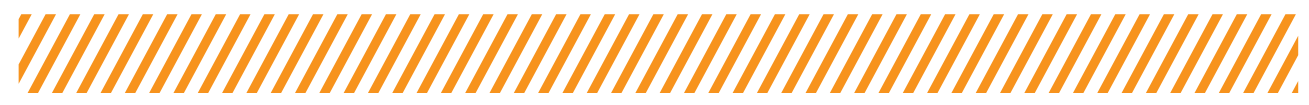

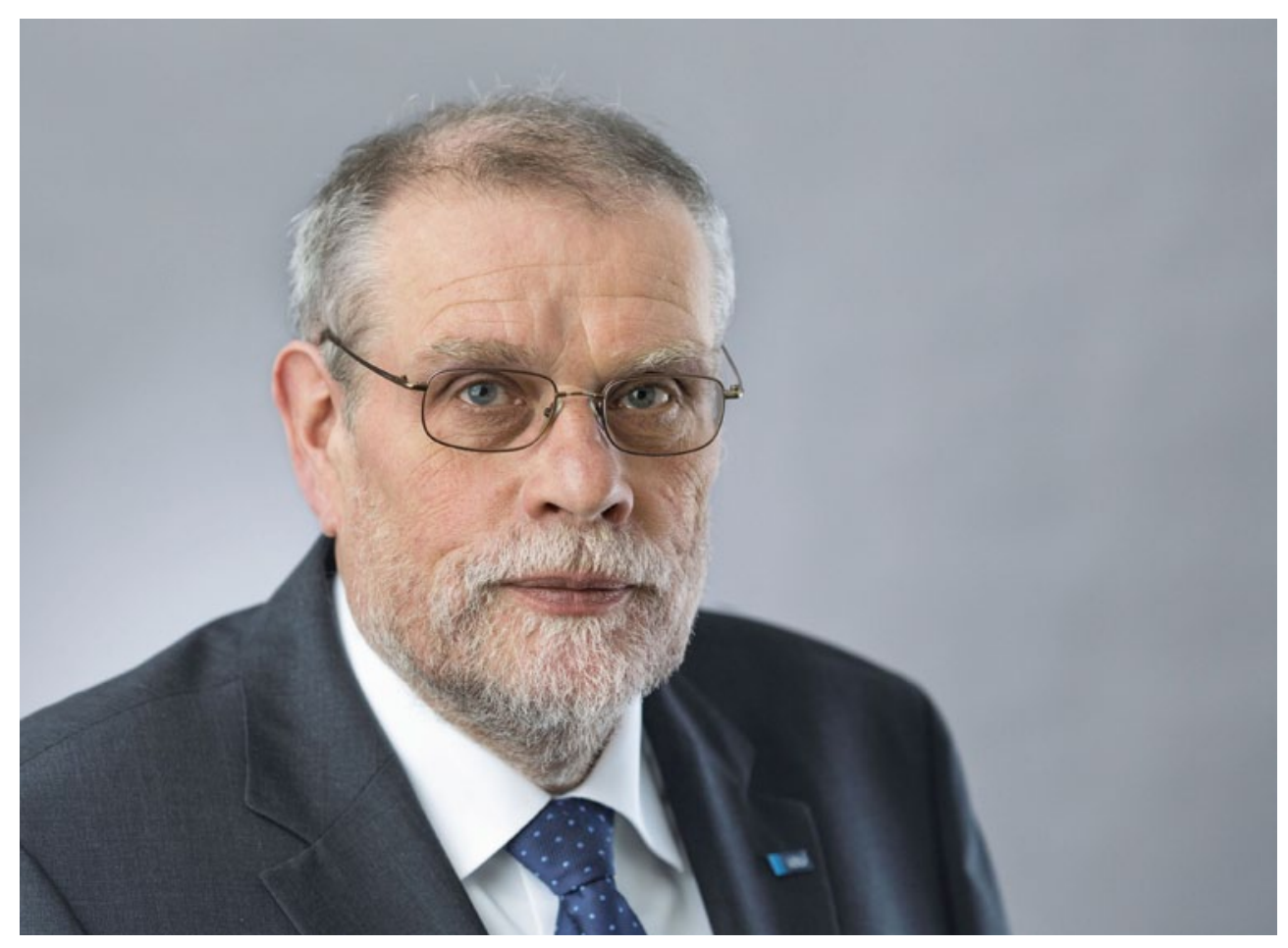

WOLFGANG REIMANN

Bereichsleiter E-Traktion (VT)

bei der IAV in Gifhorn

\section{ELEKTRISIERT IN DIE ZUKUNFT}

Das Jahr 2014 soll den Durchbruch der Elektromobilität markieren. Alle notwendigen Vorrausetzungen sind geschaffen: Der politische Wille der Bundesregierung wurde bekräftigt, viele Fahrzeughersteller haben E-Fahrzeuge im Programm und die Ladeinfrastruktur ist im Aufbau. Jetzt müssen sich nur noch die Kunden zu der neuen Antriebsart in ihrer gewohnten Mobilität bekennen und vergleichbar viel Geld dafür ausgeben.

Genau hier liegt aber das Problem einer massenhaften Verbreitung von E-Fahrzeugen. Warum sollen Autofahrer 1,5- bis 2,5-mal soviel investieren, um von A nach B zu kommen, um dann noch die Einschränkung zu akzeptieren, dass B nicht weiter als circa $150 \mathrm{~km}$ von A entfernt liegen darf? Alle möglichen Incentives wie kostenloses Parken an exponierten Stellen mit Ladesäule, mineralölsteuerfreier Strom und weniger Wartungskosten kompensieren den höheren Kaufpreis über die Nutzungsdauer nicht.

Was sind die wesentlichen Kostentreiber? In erster Linie die Batterie: Auch bei eventuell zukünftigen Preisen von 100 Euro für eine in der Batteriezelle gespeicherte Kilowattstunde ist sie bei den aktuellen 20 bis $25 \mathrm{kWh}$ im System noch teurer als ein kompletter Verbrennungsmotor. Addiert werden müssen dann noch der E-Motor und die Leistungselektronik sowie die neue Klimatisierungstechnik. Setzt man dann noch die Skaleneffekte eines in Großserie hergestellten Verbrennungsmotors in Bezug, ist der Elektroantrieb eigentlich nicht konkurrenzfähig.
Waren demnach die Entwicklungen der etablierten Automobilindustrie vergebens? Ich denke nein, da eine solche technologische Entwicklung nicht ignoriert werden kann. Tesla Motors hat gezeigt, dass in gewissen Märkten und Fahrzeugsegmenten der Bedarf für reinrassige E-Fahrzeuge vorhanden ist. Die Amerikaner haben diese Nische vortrefflich besetzt. Aufbauend auf dem Erfolg des Tesla Model S könnte sich ein Fahrzeughersteller, der nicht die Tradition des Verbrennungsmotors mitschleppt, etablieren.

Es ist daher wichtig, bereits jetzt Erfahrungen mit einer neuen Antriebstechnik in großer Breite zu sammeln, um bei geänderten politischen und volks- sowie betriebswirtschaftlichen Rahmenbedingungen reagieren zu können. So könnten beispielsweise Vorgaben für Zero Emission Vehicles oder deutliche Erhöhungen der Kraftstoffkosten die E-Traktion und Elektromobilität begünstigen.

Zur Erfüllung der gesetzlichen Anforderungen an Verbrauch ( $\mathrm{CO}_{2}$-Ausstoß der Fahrzeugflotte) und Emissionen werden auch die klassischen Verbrennungsmotoren zunehmend elektrifiziert, um in der Spanne von Micro- über Mild- zum Vollhybrid den Spagat zwischen Fahrleistung, Verbrauch und Emissionen zu ermöglichen. Das wird die Verbrennungsmotortechnik verteuern, gleichzeitig wird aber die E-Technik günstiger.

Der Weg zum E-Fahrzeug ist also möglich, die Frage ist nur: Wann rechnet es sich für Kunden und Hersteller? 